\title{
2-Octyl-cyanoacrylate for wound closure in cervical and lumbar spinal surgery
}

\author{
Dorothee Wachter • Anja Brückel • Marco Stein • \\ Matthias F. Oertel • Petros Christophis • \\ Dieter-Karsten Böker
}

Received: 2 November 2009/Revised: 7 March 2010 / Accepted: 8 March 2010/Published online: 4 May 2010

(C) The Author(s) 2010. This article is published with open access at Springerlink.com

\begin{abstract}
It is claimed that wound closure with 2-octylcyanoacrylate has the advantages that band-aids are not needed in the postoperative period, that the wound can get in contact with water and that removal of stitches is not required. This would substantially enhance patient comfort, especially in times of reduced in-hospital stays. Postoperative wound infection is a well-known complication in spinal surgery. The reported infection rates range between $0 \%$ and $12.7 \%$. The question arises if the advantages of wound closure with 2-octyl-cyanoacrylate in spinal surgery are not surpassed by an increase in infection rate. This study has been conducted to identify the infection rate of spinal surgery if wound closure was done with 2-octyl-cyanoacrylate. A total of 235 patients with one- or two-level surgery at the cervical or lumbar spine were included in this prospective study. Their pre- and postoperative course was evaluated. Analysis included age, sex, body mass index, duration and level of operation, blood examinations, 6-week follow-up and analysis of preoperative risk factors. The data were compared to infection rates of
\end{abstract}

The manuscript has not been previously published in whole or in part or submitted elsewhere for review.

The manuscript is submitted on behalf of all authors, and all named authors have participated in this work.

D. Wachter $(\bowtie) \cdot A$. Brückel • M. Stein · M. F. Oertel •

P. Christophis $\cdot$ D.-K. Böker

Department of Neurosurgery,

University Clinics of Giessen and Marburg GmbH,

Campus Giessen, Klinikstrasse 29,

35392 Giessen, Germany

e-mail: dorothee.wachter@gmx.de

D. Wachter

Department of Neurosurgery,

Georg-August-University Göttingen,

Robert-Koch-Strasse 40,

37075 Göttingen, Germany similar surgeries found in a literature research and to a historical group of 503 patients who underwent wound closure with standard skin sutures after spine surgery. With the use of 2-octyl-cyanoacrylate, only one patient suffered from postoperative wound infection which accounts for a total infection rate of $0.43 \%$. In the literature addressing infection rate after spine surgery, an average rate of $3.2 \%$ is reported. Infection rate was $2.2 \%$ in the historical control group. No risk factor could be identified which limited the usage of 2-octylcyanoacrylate. 2-Octyl-cyanoacrylate provides sufficient wound closure in spinal surgery and is associated with a low risk of postoperative wound infection.

Keywords Wound infection · Dermabond .

2-Octyl-cyanoacrylate $\cdot$ Spinal surgery

\section{Introduction}

Postoperative wound infection is a well-recognised complication in surgical procedures. In spinal surgery, postoperative infection rates were recorded between $0 \%$ and $12.7 \%[2,4,10-12,18,19,23,25,29-31,34,35,37,39]$. Postoperative wound infections cause discomfort for the patient, which may lead to a second operation, long-term use of antibiotics or prolongation of hospitalisation and additional costs to the health care system [5].

The use of 2-octyl-cyanoacrylate (Dermabond, Ethicon, Johnson \& Johnson Medical GmbH, Norderstedt, Germany) for wound closure has been widely described before. It is used in facial surgery [7,9], craniotomy or craniectomy [6], corneal surgery [22], repairing of peripheral nerves [27], orthopaedic surgery [21], neck surgery [29], hand surgery [16] or mammoplasties [33], just to name a few recently published studies. According to these studies, the use of 
2-octyl-cyanoacrylate allows wound management without any band-aids, even if the wound would possibly get in contact with water. Furthermore, removal of stitches is not required, alleviating at least one patient-surgeon contact. Up to date, the experience with the use of 2-octyl-cyanoacrylate in spinal surgery is very limited [15], especially if risk factors and the course of operation are additionally addressed.

In the present study, 2-octyl-cyanoacrylate was used for wound closure in one- and two-level spinal surgery cases. The study was designed as a cross-sectional study to record the incidence of wound infections after spine surgery. In addition, limitations and risk factors for the use of 2-octylcyanoacrylate were investigated.

\section{Materials and methods}

Patients

Two hundred thirty-five consecutive patients (136 men, 99 women; median age 60 years, range 25-84 years) were recruited in this prospective clinical study. All patients who underwent one- or two-level surgery at the cervical or lumbar spine were included. Previous surgery, systemic diseases or emergency surgeries were no exclusion criteria. Every operation was done with the aid of an operating microscope. Two hundred thirteen patients $(90.6 \%)$ were available for 6-week follow-up.

Fifty patients $(21.3 \%)$ each underwent surgery at the cervical spine for one- or two-level ventral fusion. Fifty patients $(21.3 \%)$ underwent lumbar disc surgery; 49 (20.1\%) and 31 patients (13.2\%) had surgery for one-level and two-level lumbar stenosis, respectively. In five patients (2.1\%), re-operation for recurrent lumbar disc disease was performed (Table 1). Thus, the length of the skin incision was between 3 and $6 \mathrm{~cm}$ in the vast majority of the patients. Two hundred twenty-three patients $(94.4 \%)$ received perioperative prophylactic antibiotic therapy with cefazolin ( 2 or $4 \mathrm{~g}$ ), 11 patients $(4.7 \%)$ with clindamycin $(0.6$ or $0.9 \mathrm{~g})$ and one patient $(0.4 \%)$ was treated with amoxicillin $(1.0 \mathrm{~g})$. The following additional data were recorded: patients' age, body mass index (BMI), duration of operation, usage of wound drainage, pre- and postoperative laboratory analysis, preexisting diseases, wound condition and 6-week follow-up.

The data were compared to infection rates of similar surgeries found in a literature research (Table 4) and to a historical group of 503 patients, who underwent spine surgery and standard sutured skin closure at our institution. Four hundred and forty of the 503 patients $(87.5 \%)$ were operated on for cervical $(n=62)$, thoracic $(n=2)$ or lumbar disc disease $(n=338), 38$ patients for recurrent disc disease,
Table 1 Types and course of operation

\begin{tabular}{lll}
\hline Cervical spine & $n$ & $\%$ \\
Cervical spine & 100 & $43 \%$ \\
One level & 50 & $21 \%$ \\
Two level & 50 & $21 \%$ \\
Lumbar spine & $n$ & $\%$ \\
Herniated disc disease & 55 & $23 \%$ \\
First operation & 50 & $21 \%$ \\
Recurrent & 5 & $2 \%$ \\
Stenosis & 80 & $34 \%$ \\
One level & 49 & $21 \%$ \\
Two level & 31 & $13 \%$ \\
Duration & & \\
Average duration (min) & 106.5 & \\
Range (min-max) & $33-489$ & \\
Wound drainage & $n$ & $67 \%$ \\
Yes & 157 & $100 \%$ \\
Six-week follow-up & $n$ & \\
Regular wound condition & 134 & \\
\hline
\end{tabular}

22 patients for lumbar stenosis $(4.4 \%), 30$ patients $(6.0 \%)$ for epidural spinal tumour and 11 patients $(2.2 \%)$ for spinal fractures. Those data had been published in a doctoral thesis regarding the postoperative wound infection rate with and without perioperative antibiotic prophylaxis in cranial and spinal operations [32].

Wound closure and postoperative wound management

Wound closure was performed with 2-octyl-cyanoacrylate in all cases. After placing subcutaneous sutures for wound adaptation and approximation of the skin edges, 2-octylcyanoacrylate was applied for skin adhesion. After crushing the inner ampoule, 2-octyl-cyanoacrylate was pumped into the applicator and finally applied to the adapted wound edges in multiple layers. Its liquid form polymerised to solid form after 2-3 min (Fig. 1). The wound was covered with a band-aid to avoid adherence to bedding layers. The band-aid was removed on the first postoperative day, no further band-aids were used. Approximately after 1 week, 2-octyl-cyanoacrylate automatically dissoluted. The patients were allowed to take a shower on the first postoperative day. As removal of stitches was not required, the patients were not advised to seek again medical contact for wound care.

Statistical analysis

Statistical analysis had been performed using Statistica Version 8 (Statsoft Software Hamburg, Germany). Statistical significance was defined as $p<0.05$. 

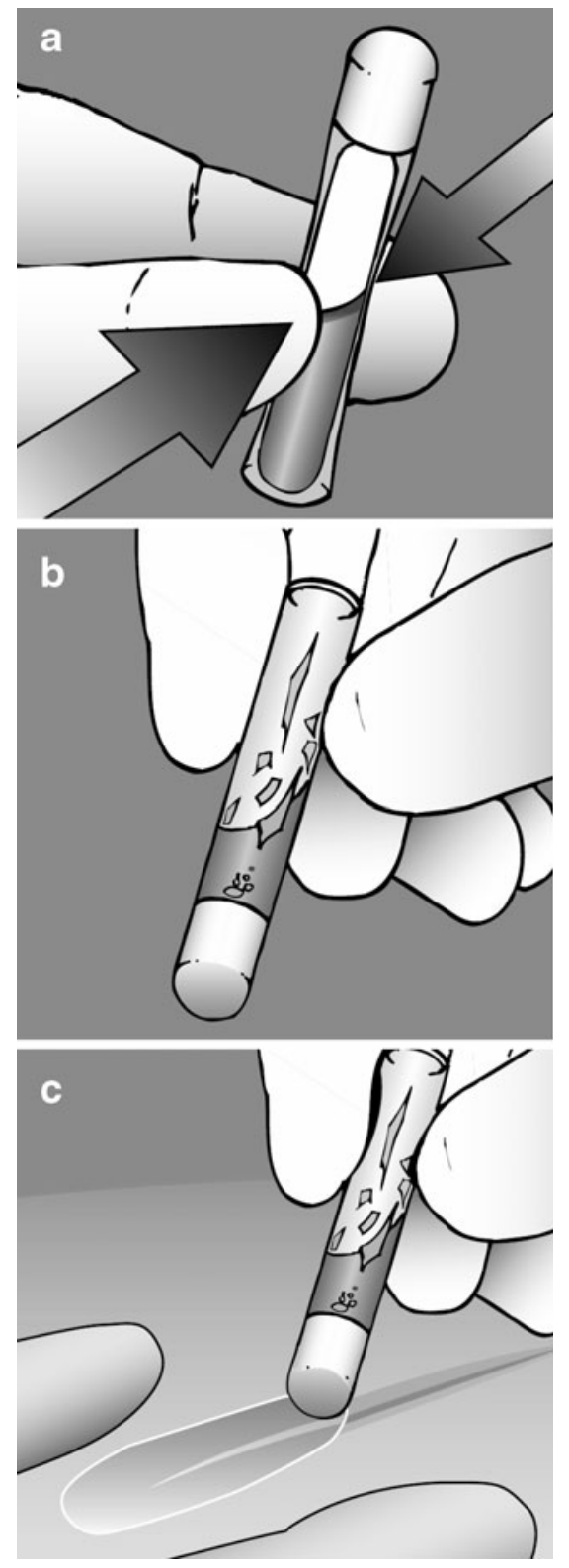

Fig. 1 Use of 2-octyl-cyanoacrylate (Dermabond ${ }^{\circledR}$ ). After crushing the inner ampoule (a), Dermabond is being pumped into the applicator (b) and finally applied to the adapted wound edges in multiple layers (c). Its liquid form polymerises rapidly to solid form (illustration provided by Ethicon, Inc.)

\section{Results}

In 235 patients, skin closure was performed with 2-octylcyanoacrylate after anterior cervical $(n=100)$ and dorsal lumbar $(n=135)$ spinal surgery. The average duration of operation was $106.5 \mathrm{~min}$ (range 33-489 $\mathrm{min}$ ) (Table 1). In 157 patients $(67 \%)$, wound drainage was used for 1 day. The patients' average BMI was 28 (range 18-49). Coexisting diseases were high blood pressure $(49 \% ; n=114)$, smoking $(24 \% ; n=57)$, diabetes mellitus $(17 \% ; n=40)$, chronic obstructive lung disease $(7 \% ; n=17)$, cardiac insufficiency
$(3 \% ; n=8)$ and malignant tumours $(3 \% ; n=8)$ (Table 2). No foreign-body reaction occurred; wound conditions had been regular with satisfactory cosmetic results in all patients that were available for 6-week follow-up $(90.6 \%)$.

Age $(p=0.254)$ as well as arterial hypertension $(p=$ 0.304 ) did not show statistical significance as risk factors in cases of wound closure with 2-octyl-cyanoacrylate.

The overall infection rate was $0.43 \%$ with only one 79 year-old female patient developing wound infection with Staphylococcus aureus after one-level decompression for lumbar spinal stenosis (Table 3). Duration of operation was $63 \mathrm{~min}$. The laboratory analysis after decompression only revealed slightly elevated infection parameters (c-reactive protein of $27 \mathrm{mg} / \mathrm{dl}$ ) and leucocytes on a regular basis. The only preexisting disease had been high arterial blood pressure. The patient's BMI was within regular ranges $(B M I=25)$. She underwent wound revision with an uneventful course after the second operation.

Overall infection rate in the historic control group after spinal surgery including cervical, thoracic and lumbar spinal procedures was $2.8 \%$ without perioperative antibiotic treatment and $2.2 \%$ with perioperative antibiotic treatment (single-shot antibiotic treatment with either cephazolin, clindamycin or ampicillin). In the literature addressing infection rates after spine surgery, an average rate of 3.2\% has been reported (Table 4).

\section{Discussion}

In 1959, Coover et al. originally reported the chemistry and performance of cyanoacrylate and its use as tissue adhesive

Table 2 Patient population

\begin{tabular}{lll}
\hline Age & & \\
Average age (years) & 60.4 & \\
Range & $25-84$ & $\%$ \\
Gender & $n$ & $42.1 \%$ \\
Female & 99 & $57.9 \%$ \\
Male & 136 & $\%$ \\
Risk factors & $n$ & $17 \%$ \\
Diabetes & 40 & $3 \%$ \\
Heart insufficiency & 8 & $7 \%$ \\
Obstructive lung disease & 17 & $0 \%$ \\
Chronic infections & 0 & $3 \%$ \\
Malignoma & 8 & $49 \%$ \\
Hypertonic disease & 114 & $24 \%$ \\
Smoker & 57 & \\
BMI & & \\
Average BMI & 28.0 & \\
Range & $18-49$ & \\
\hline
\end{tabular}


for surgical procedures [8]. In the beginning, a long-chained octyl-2-cyanoacrylate tissue adhesive was compared to two short-chained ethyl-2- and butyl-2-cyanoacrylates. Skin samples (pig model) were tested for the tensile strength of their wound stability, and cell culture tests were used to show the toxic effects of the three cyanoacrylates. In a copper test, 2-octyl-cyanoacrylate was more stable than ethyl- and butyl-cyanoacrylates. Breaking strength was $30 \%$ lower 28 days after operation with the new product than with sutures. In electron microscopy, 2-octylcyanoacrylate showed no disadvantages with regard to tissue regeneration and no histotoxicity [24]. In 1998, the Food and Drug Administration approved $n$-2-butylcyanoacrylate as 2octyl-cyanoacrylate $[6,13]$.

Regarding patients' comfort, 2-octyl-cyanoacrylate theoretically offers several advantages. There is no need for band-aids or waterproof band-aids for showering and no removal of sutures or staples is required. Since its introduction, numerous applications have been described $[6,7,9,15,16,21,22,26,28,33,38]$. It is used in facial surgery $[7,9,38]$, craniotomy or craniectomy [6], corneal surgery [22], repairing of peripheral nerves [26], orthopaedic surgery [21], neck surgery [28], hand surgery [16] or mammoplasties [33], just to name a few recently published studies. Ellis et al. compared the use of fibrin glue and 2octyl-cyanoacrylate in facial plastic and reconstructive surgery and concluded that cyanoacrylate is the ideal tissue adhesive for surface cutaneous wound closure in regards to safety, reliability, tensile strength and cost effectiveness [9]. Hancock et al. performed a prospective observational study of the use of 2-octyl-cyanoacrylate in hand surgery. Wound complication rate was low (one adverse event) and all patients were satisfied (46\%) or very satisfied (54\%) with wound healing and the cosmetic result. They concluded that routine postoperative wound review in these patients might not be needed, thereby saving time and resources [16]. Scott et al. [33] reviewed 255 consecutive bilateral reduction mammoplasties performed by a single surgeon with 2-octyl-cyanoacrylate used for skin closure and compared those data with an earlier review of 415 reduction mammoplasties using standard sutured skin closures. 2Octyl-cyanoacrylate was associated with decreased operative times, a decreased rate for minor $(1.18 \%)$ and major wound dehiscence $(0.78 \%)$ and less hypertrophic scar revisions $(2.75 \%)$.

Wilson and Mercer compared the use of 2-octylcyanoacrylate with thin adhesive strips (Steri-Strips ${ }^{\mathrm{TM}}$ ) in unilateral cleft lip repair. They found a lower infection and revision rate and a similar hypertrophic scar rate when 2octyl-cyanoacrylate was used [38].

Wang et al. have described the first clinical use of 2octyl-cyanoacrylate for wound closure in neurosurgical procedures in paediatric neurosurgery [36].

Since spinal surgical interventions cannot be compared with corneal surgery, mammoplasties, facial surgery or craniotomies regarding postoperative wound infections, the question arises if the benefits of 2-octyl-cyanoacrylate are being outweighted by an increasing risk of surgical site infections. Especially in lumbar spinal surgery, patients often present with an exalted BMI with increased perspiration, which are well-known factors closely related to a higher number of wound healing abnormalities $[1,14,17$, $18,20,21,25]$. In addition, rest in supine position on the wound after lumbar spine surgery has the potential leading to the formation of humid chambers which can result in wound breakdown and infection. Thus, it seems possible that the patients who underwent spine surgery do not benefit from the advantages of 2-octyl-cyanoacrylate and that its use is especially contraindicated in patients who have co-morbidities such as diabetes mellitus or hyperten-

Table 3 Occurrence of postoperative wound infection in cervical and lumbar spinal surgery

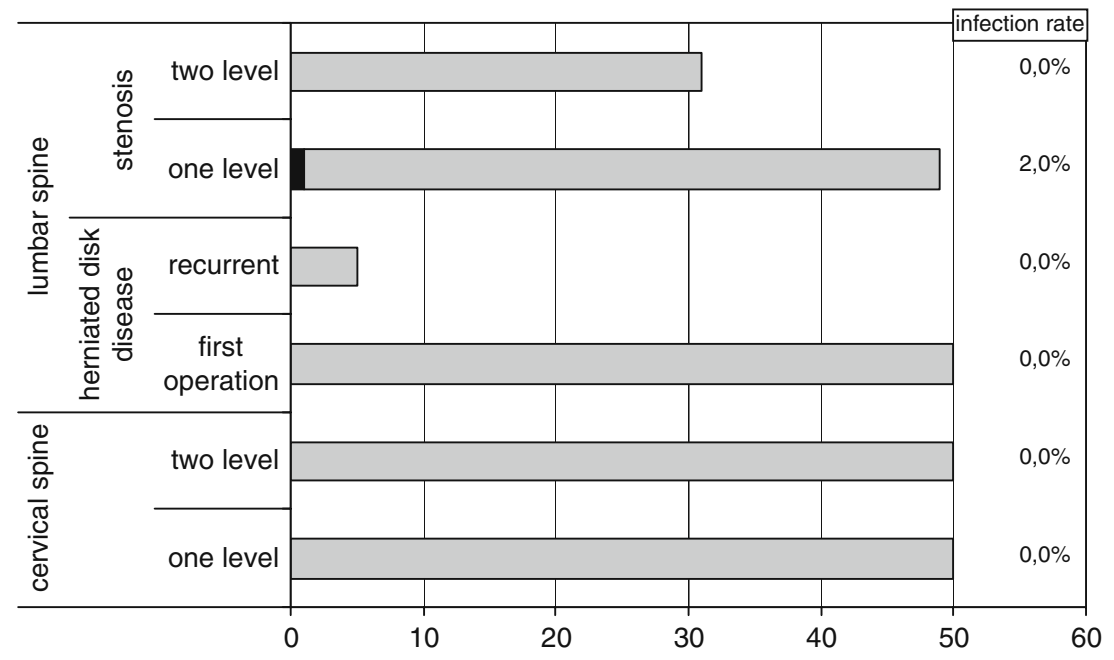


sion which are well-known risk factors of postoperative infections [10, 11, 34, 39].

Former studies have demonstrated wound infection rates after spinal surgery between $0 \%$ and $12.7 \%$, with a mean infection rate of $3.2 \%[2,4,10,12,18,19,23,25,29,31$, $34,35,37,39]$ as demonstrated in Table 4. With an infection rate of $0.43 \%$, our results clearly demonstrate that even patients with a high BMI and further risk factors do not have an increased risk of postoperative wound infections, once 2-octyl-cyanoacrylate is being used for wound closure (Table 3). Possibly, the low infection rate of 2-octyl-cyanoacrylate is the result of antimicrobial properties against gram-positive organisms [27] and/or of the sterile and occlusive liquid cover of 2-octyl-cyanoacrylate [3] which prevents the formation of humid compartments. This is supported by the finding that the infection rate was substantially lower in the 2-octyl-cyanoacrylate group $(0.43 \%)$ than in the historical control group, in which standard suture skin closure was performed (2.2\%) [32]. Since we limited our study to the use of 2-octylcyanoacrylate in spinal surgical procedures, we cannot make a statement on its use in other neurosurgical procedures. However, good results have been reported in paediatric neurosurgery and craniotomy or craniectomy [6, 36]. Further studies are needed to make clear statements on the use of 2-octyl-cyanoacrylate in cranial neurosurgical procedures compared to standard suture skin closure.

Furthermore, the study does not allow to define up to which lengths of skin incision 2-octyl-cyanoacrylate is an effective and safe alternative to sutures, as the vast majority of patients have had skin incisions between 3 and $6 \mathrm{~cm}$.

We cannot definitively prove that the low infection rate is attributable to the use of 2-octyl-cyanoacrylate, but our results demonstrate the advantages of this liquid wound closure with a low rate of surgical site infections, even in patients with risk factors for surgical interventions.

Table 4 Characteristics of the selected analyses on antibiotic prophylaxis in the prevention of surgical site infections in neurosurgical procedures

\begin{tabular}{|c|c|c|c|c|}
\hline Series (ref. no.) & Study design & No. of patients & Antibiotic prophylaxis & Infection rates \\
\hline Mastronardi et al. [23] & $\begin{array}{l}\text { Prospective study } \\
\text { (microdiscectomy) }\end{array}$ & $\begin{array}{l}450 \text { (group 1) } \\
705 \text { (group 2) }\end{array}$ & $\begin{array}{l}\text { Group 1: cephazolin+rifamycin } \\
\text { Group 2: ampicillin }+ \text { sulbactam }\end{array}$ & $\begin{array}{l}\text { Group 1: } 0.67 \% \\
\text { Group 2: } 0.69 \%\end{array}$ \\
\hline Olsen et al. [25] & $\begin{array}{l}\text { Retrospective case-control } \\
\text { study (laminectomy and/or } \\
\text { spinal fusion) }\end{array}$ & 219 & Different antibiotic regimen & $2.8 \%$ \\
\hline Weinstein et al. [38] & $\begin{array}{l}\text { Retrospective analysis (single } \\
\text { surgeon, spinal surgery) }\end{array}$ & 2,391 & Cephalothin or vancomycin & $1.9 \%$ \\
\hline Fang et al. [37] & $\begin{array}{l}\text { Retrospective case-control } \\
\text { study (spinal surgery) }\end{array}$ & 1,629 & $\begin{array}{l}\text { First generation cephalosporin } \\
\text { (continued for } 48 \mathrm{~h} \text {, except in } \\
\text { simple spinal decompression) }\end{array}$ & $4.4 \%$ \\
\hline Blam et al. [4] & $\begin{array}{l}\text { Retrospective analysis } \\
\text { (elective spinal surgery } \\
\text { and spinal injury) }\end{array}$ & $\begin{array}{l}256 \text { (patients with } \\
\text { spinal injury) } \\
2,990 \text { (elective } \\
\text { spinal surgery) }\end{array}$ & Not specified & $\begin{array}{l}9.4 \% \text { (spinal injury) } \\
3.7 \% \text { (elective surgery) }\end{array}$ \\
\hline Schnöring et al. [32] & $\begin{array}{l}\text { Retrospective analysis } \\
\text { (lumbar disc surgery) }\end{array}$ & 963 & $\begin{array}{l}\text { Group 1: cefotiam } \\
\text { Group 2: no antibiotics }\end{array}$ & $\begin{array}{l}\text { Group 1: } 0.2 \% \\
\text { Group 2: } 2.8 \%\end{array}$ \\
\hline Rubinstein et al. [30] & $\begin{array}{l}\text { Double-blinded randomised } \\
\text { study (lumbar spinal surgery) }\end{array}$ & 166 & $\begin{array}{l}\text { Group 1: cephazolin } 1 \mathrm{~g} \\
\text { Group 2: placebo }\end{array}$ & $\begin{array}{l}\text { Group 1: } 4.3 \% \\
\text { Group 2: } 12.7 \%\end{array}$ \\
\hline Takahashi et al. [34] & Prospective study (spinal surgery) & 1,415 & $\begin{array}{l}\text { Group 1: ABP for } 7 \text { days (postop) } \\
\text { Group 2: periop and } 5 \text { days postop } \\
\text { Group 3: periop and } 3 \text { days postop } \\
\text { Group 4: periop and } 2 \text { days postop }\end{array}$ & $\begin{array}{l}\text { Group 1: } 2.6 \% \\
\text { Group 2: } 0 \% \\
\text { Group 3: } 0 \% \\
\text { Group 4: } 0 \%\end{array}$ \\
\hline Valentini et al. [36] & $\begin{array}{l}\text { Prospective clinical series } \\
\text { (neurosurgical procedures) }\end{array}$ & $\begin{array}{l}1,747 \text { (663 spinal } \\
\text { operations) }\end{array}$ & $\begin{array}{l}\text { Four categories: } \\
\text { Clean: cephazolin } \\
\text { Clean-contaminated: } \\
\text { cephazolin+metronidazole } \\
\text { Ventriculoperitoneal shunt } \\
\text { Other procedures }\end{array}$ & $\begin{array}{l}0.72 \%(0.15 \% \text { in } \\
\text { spinal operations })\end{array}$ \\
\hline
\end{tabular}

$A B P$ antibiotic prophylaxis

Table 4 shows the characteristics of a selected series of published articles concerning postoperative wound infections in spinal procedures. Wound infection rates were between $0 \%$ and $12.7 \%$. Mean infection rate has been calculated as $3.2 \%$. Data show the type of antibiotic prophylaxis, type of study, number of patients included and the individual infection rate 
Strengths and limitations of the study

The strengths of the present study are the non-selective inclusion of consecutive patients with cervical and lumbar spinal degenerative disease and the prospective data collection. The major limitation is that the comparison of the infection rate in the present series was only possible with an institutional historical series and with the literature. The decision to switch from sutures to 2-octyl-cyanoacrylate was made on economical criteria. A randomised trial is needed to underline the convincing results of the present study.

\section{Conclusion}

2-Octyl-cyanoacrylate provides sufficient wound closure in spinal surgery and is associated with a low risk of postoperative wound infection.

Disclaimer The authors do not report any conflict of interest concerning the materials or methods used in this study or the findings specified in this paper.

Open Access This article is distributed under the terms of the Creative Commons Attribution Noncommercial License which permits any noncommercial use, distribution, and reproduction in any medium, provided the original author(s) and source are credited.

\section{References}

1. Andreshak T, An HS, Hall J et al (1997) Lumbar spine surgery in the obese patient. J Spinal Disord 10:376-379

2. Barker FG 2nd (2002) Efficacy of prophylactic antibiotic therapy in spinal surgery: a meta-analysis. Neurosurgery 51:391-401

3. Bhende S, Rothenburger S, Spangler DJ et al (2002) In vitro assessment of microbial barrier properties of Dermabond topical skin adhesive. Surg Infect (Larchmt) 3:251-257

4. Blam OG, Vaccaro AR, Vanichkachorn JS et al (2003) Risk factors for surgical site infection in the patient with spinal injury. Spine 28(13): 1475-1480

5. Calderone RR, Garland DE, Capen DA et al (1996) Cost of medical care for postoperative spinal infections. Ortho Clin North Am 27(1):171-182

6. Cho J, Harrop J, Veznadaroglu E et al (2003) Concomitant use of computer image guidance linear or sigmoid incisions after minimal shave, and liquid wound dressing with 2-octylcyanoacrylate for tumor craniotomy or craniectomy: analysis of 225 consecutive surgical cases with antecedent historical control at one institution. Neurosurgery 52(4):832-841

7. Collin TW, Blyth K, Hodgkinson PD (2009) Cleft lip repair without suture removal. J Plast Reconstr Aesthet Surg 62(9):1161-1165

8. Coover H, Joyner F, Sheerer N et al (1959) Chemistry and performance of cyanoacrylate adhesive. Special Technical Papers 5:413-417

9. Ellis DA, Shaikh A (1990) The ideal tissue adhesive in facial plastic and reconstructive surgery. J Otolaryngol 19:68-72

10. Erman T, Demirhindi H, Göcer AI et al (2005) Risk factors for surgical site infections in neurosurgery patients with antibiotic prophylaxis. Surg Neurol 63(2):107-112
11. Fang A, Hu SS, Endres $\mathrm{N}$ et al (2005) Risk factors for infection after spinal surgery. Spine 30(12):1460-1465

12. Friedman ND, Sexton DJ, Connelly SM et al (2007) Risk factors for surgical side infection complicating laminectomy. Infect Control Hosp Epidemiol 28(9):1060-1065

13. Galil KA, Schofield ID, Wright GZ (1984) Effect of n-butyl-2cyanoacrylate (histoacryl blue) on the healing of skin wounds. J Can Dent Assoc 50:565-569

14. Gepstein R, Shabat S, Arinzon ZH et al (2004) Does obesity affect the results of lumbar decompressive spinal surgery in the elderly? Clin Orthop Relat Res 426:138-144

15. Hall LT, Bailes JE (2005) Using Dermabond for wound closure in lumbar and cervical neurosurgical procedures. Neurosurgery 56 (Suppl 1):147-150

16. Hancock NJ, Samuel AW (2007) Use of Dermabond tissue adhesive in hand surgery. J Wound Care 16(10):441-443

17. Hanigan W, Elwood PW, Henderson JP et al (1987) Surgical results in obese patients with sciatica. Neurosurgery 20:896-899

18. lbusch LC, Helzer-Julin M, Doran SE (2008) Single-dose vs multiple-dose antibiotic prophylaxis in instrumented lumbar fusion-a prospective study. Surg Neurol 70:622-627

19. Jones J (2005) Prophylactic antibiotic use in clean neurosurgery: of potential benefit or harm to the patient? J Wound Care 14(1):39-41

20. Klekner A, Ga'spa'r A, Kardos S et al (2003) Cefazolin prophylaxis in neurosurgery monitored by capillary electrophoresis. J Neurosurg Anesthesiol 15(3):249-254

21. Lee J, Singletary R, Schmader K et al (2006) Surgical site infection in the elderly following orthopaedic surgery. Risk factors and outcomes. Bone Joint Surg Am 88(8):1705-1712

22. Leung GY, Peponis V, Varnell ED et al (2005) Preliminary in vitro evaluation of 2-octyl-cyanoacrylate (Dermabond) to seal corneal incisions. Cornea 24(8):998-999

23. Mastronardi L, Tatta C (2004) Intraoperative antibiotic prophylaxis in clean spinal surgery: a retrospective analysis in a consecutive series of 973 cases. Surg Neurol 61(2):129-135

24. Nitsch A, Pabyk A, Honig JF et al (2008) Cellular, histomorphologic, and clinical characteristics of a new octyl-2-cyanoacrylate skin adhesive. Aesthet Plast Surg 29(1):53-58

25. Olsen MA, Mayfield J, Lauryssen C et al (2003) Risk factors for surgical site infection in spinal surgery. J Neurosurg $98(2$ Suppl):149-155

26. Pineros-Fernandez A, Rodeheaver PF, Rodeheaver GT (2005) Octyl 2-cyanoacrylate for repair of peripheral nerve. Ann Plast Surg 55(2):188-195

27. Quinn JV, Osmond MH, Yurack JA et al (1995) N-2butylcyanoacrylate: risk of bacterial contamination with an appraisal of its antimicrobial effects. J Emerg Med 13:581-585

28. Ridgway DM, Mahmood F, Moore L et al (2007) A blinded, randomized, controlled trial of stapled versus tissue glue closure of neck surgery incisions. Ann R Coll Surg Engl 89(3):242-246

29. Rubinstein E, Findler G, Amit $P$ et al (1994) Perioperative prophylactic cephazolin in spinal surgery. J Bone Joint Surg 76-B:99-102

30. Savitz MH, Malis LI, Savitz SI (2003) Efficacy of prophylactic antibiotic therapy in spinal surgery: a meta-analysis. Neurosurgery 53(1):243-244

31. Schnöring M, Brock M (2003) Prophylactic antibiotics in lumbar disc surgery: analysis of 1,030 procedures. Zentralbl Neurochir 64(1):24-29

32. Schiel CG (1997) Untersuchung zur möglichen Auswirkung einer präoperativen Antibiotikaprophylaxe auf die spätere Wundheilung nach neurochirurgischen Eingriffen. Inaugural-Dissertation des Fachbereiches Humanmedizin der Justus-Liebig-Universität Giessen; 16.11

33. Scott GR, Carson CL, Borah GL (2007) Dermabond skin closures for bilateral reduction mammoplasties: a review of 255 consecutive cases. Plast Reconstr Surg 120(6):1460-1465

34. Takahashi H, Wada A, Iida Y et al (2009) Antimicrobial prophylaxis for spinal surgery. J Orthop Sci 14:1296-1305 
35. Valentini LG, Casali CC, Chatenoud L et al (2008) Surgical site infections after elective neurosurgery: a survey of 1747 patients. Neurosurgery 62(1):88-96

36. Wang MY, Levy ML, Mittler MA et al (1999) A prospective analysis of the use of octylcyanoacrylate tissue adhesive for wound closure in pediatric neurosurgery. Pediatr Neurosurg 30:186-188

37. Weinstein MA, McCabe JP, Cammisa FP Jr (2000) Postoperative spinal wound infection: a review of 2391 consecutive index procedures. J Spinal Disord 13(5):422-426

38. Wilson AD, Mercer N (2008) Dermabond tissue adhesive versus Steri-Strips in unilateral cleft lip repair: an audit of infection and hypertrophic scar rates. Cleft Palate Craniofac J 45(6):614-619

39. Wimmer C, Gluch H, Franzreb $M$ et al (1998) Predisposing factors for infection in spine surgery: a survey of 850 spinal procedures. J Spinal Disord 11:124-128

\section{Comments}

\section{Ralf A. Kockro, Zurich, Switzerland}

This is an interesting report about the experiences with 2-octylcyanoacrylate for wound closure in cervical and lumbar surgery. In 235 consecutive patients operated on in one institution, the authors report one case $(0.43 \%)$ of postoperative wound infection and overall a good cosmetic outcome. This is an excellent result compared to the commonly reported infection rate of approximately $3 \%$, and it approximately halves the infection rate of my own experiences with "Steri-Strip" wound closure for one-level lumbar spinal surgery. Technological advances offer chances of significant treatment benefits and are worthy of bias-free evaluation. Once the results are verified in larger series, this technique has good chances to be adopted broadly.

\section{Claudius Thomé, Innsbruck, Austria}

Dr. Wachter et al. present a monocentric prospective study on the use of 2-octyl-cyanoacrylate in 235 consecutive patients treated by mono- or bisegmental anterior cervical or posterior lumbar spine surgery. The infection rate of $0.4 \%$ compares favourably to literature data and to an infection rate of $2.2 \%$ found in a historical control group of 503 patients with standard suture-based wound closure at the same institution. All patients available for 6-week follow-up $(90.6 \%)$ demonstrated a satisfactory cosmetic result.

The authors report convincing results of a simple and intelligent study. Obviously, this is not a randomized controlled trial, but with a substantial number of patients collected consecutively it provides evidence that this is a valid alternative to sutures. 2-octyl-cyanoacrylate has been regularly used in other surgical disciplines and by many spine surgeons due to the obvious advantages particularly for patient comfort. The authors are to be congratulated for their prospective analysis of spine cases.

Nevertheless, it has to be stressed that the patient cohort is limited to small incisions, extradural procedures and particular regions. Posterior cervical procedures have not been included. In my personal experience, 2-octyl-cyanoacrylate in posterior cervical surgery tends to produce somewhat wider scars, which may be due to the increased tension on the respective skin upon motion. The lack of a structured evaluation of the cosmetic result represents one limitation of the present study. It should be also mentioned that the use of 2-octylcyanoacrylate requires more meticulous suturing of the subcutaneous layer to perfectly align the skin edges. Overall, however, this study adds important and practical data to the literature. 